\title{
VALORIZAÇÃO DOS PROFISSIONAIS DE CONTABILIDADE COMO CONSULTORES
}

\author{
João Guilherme Mazzaro Lopes ${ }^{1}$ \\ Thiago Okumura Zanetoni ${ }^{2}$ \\ Tiago de Oliveira Lopes ${ }^{3}$ \\ Daniela Boreli ${ }^{4}$
}

RESUMO: A demanda de procura dos serviços contábeis tem caído absurdamente, docentes da área acreditam que esse fato é justificado a partir da hipótese de que a educação contábil esteja desatualizada, principalmente ao que tange aos professores, motivo no qual existe grande necessidade de mudanças relevantes. Nota-se que a necessidade de novas competências aos profissionais da área contábil, principalmente as que estão associadas às habilidades da área tecnológica. observou a necessidade de novas competências aos profissionais da área contábil, principalmente as que estão associadas às habilidades da área tecnológica. Vale evidenciar que a compreensão a cerca dessas lacunas é evidenciada em todas as áreas de atuação das ciências contábeis, principalmente na contabilidade financeira e gerencial. $O$ desenvolvimento desse trabalho foi motivado a partir da grande necessidade de evidenciar a atividade deliberada do profissional contábil sobre a empresa ao qual presta serviços e ressaltar diversos fatores que podem contribuir para organização. Por meio de uma revisão de bibliográfica de cunho descritivo, buscou-se compreender a necessidade brasileira quanto à atuação da consultoria contábil na rotina empresarial.

Palavras-Chave: Contabilidade. Profissionais. Serviços Contábeis.

\footnotetext{
Acadêmico Graduando em Ciências Contábeis pela Fundação Educacional de Fernandópolis Joao-guilherme-lopes@hotmail.com

2 Acadêmico Graduando em Ciências Contábeis pela Fundação Educacional de Fernandópolis Thiagozanetoni.tz@gmail.com

3 Acadêmico Graduando em Ciências Contábeis pela Fundação Educacional de Fernandópolis To487504@gmail.com

${ }^{4}$ Professora Mestre-Orientadora da Fundação Educacional de Fernandópolis

daniboreli@hotmail.com
} 


\section{INTRODUÇÃO}

Diversos estudos têm sido realizados nos últimos anos a respeito da educação contábil e seu papel no mercado, os resultados concluem que existe a grande necessidade de mudanças no ensino contábil. Segundo Albrecht e Sack (200o), nos Estados Unidos, a demanda de procura dos serviços contábeis tem caído absurdamente, docentes da área acreditam que esse fato é justificado a partir da hipótese de que a educação contábil esteja desatualizada, principalmente ao que tange aos professores, motivo no qual existe grande necessidade de mudanças relevantes.

Corroborando com esse achado, Howieson (2003), observou a necessidade de novas competências aos profissionais da área contábil, principalmente as que estão associadas às habilidades da área tecnológica. Em contrapartida, Humprey (2005) acredita que cada país tem suas peculiaridades quanto aos contextos e experiências na educação contábil, entretanto, o foco quanto aos aspectos éticos tem se tornado frequentes após o período Enron.

Para Miranda et al. (2011), não é incomum encontrar estudos que argumentem sobre o ensino contábil, principalmente discussões que são norteadas à lacuna, onde GAP é o termo comumente encontrado mundialmente, no qual existe entre o mercado e os cursos da área das ciências contábeis nas instituições de ensino do nível superior, onde tem contribuído para a oferta de conteúdo aos alunos da área, adequando-os à realidade das atividades desenvolvidas na profissão. Vale ressaltar que a compreensão a cerca dessas lacunas é evidenciada em todas as áreas de atuação das ciências contábeis, principalmente na contabilidade financeira e gerencial.

Compreende-se por contabilidade gerencial a atividade que foca sua atividade no atendimento da demanda de usuários internos de empresas, nas quais podem ser atendidas por meio de relatórios gerenciais no tocante de decisões. O exercício dessa atividade está para a composição do processo, que visa identificar, mensurar, acumular, analisar, preparar, interpretar e comunicar a respeito das informações a fim de gerar comunicação entre os usuários internos, contribuindo para o suporte do processo de tomada de decisões e conexão com os objetivos da organização (FREZATTI et al., 2007). 
Ekbatani e Sangeladji (2008) acreditam que na contabilidade gerencial é possível observar estudos a respeito das lacunas observadas entre o corpo docente e os profissionais em campo quanto suas atividades, artefatos de trabalho e suas competências fundamentais para seu desenvolvimento. Entretanto, no Brasil, não são observados estudos dessa linhagem.

O desenvolvimento desse trabalho foi motivado a partir da grande necessidade de evidenciar a atividade deliberada do profissional contábil sobre a empresa ao qual presta serviços e ressaltar diversos fatores que podem contribuir para organização. Por meio de uma revisão de bibliográfica de cunho descritivo, buscou-se compreender a necessidade brasileira quanto à atuação da consultoria contábil na rotina empresarial.

\section{BREVE HISTÓRICO E EVOLUÇÃO DA CONTABILIDADE}

A contabilidade moderna surgiu oficialmente na Itália, durante o período da renascença, conforme defendido por Hendriksen e Van Breda (1999, p. 39), contudo, ela desabrochou em virtude da criação do princípio das partidas dobradas, que se baseia no fato de que todo crédito sempre corresponde a um débito de igual valor e vice-versa. A era científica da contabilidade iniciou durante o século XVIII, a partir do estudo de aspectos patrimonialistas e da necessidade do conhecimento de sua natureza, fomentada pelo predominante sistema do capitalismo. A contabilidade, a partir dessa época, considerada como ciência, se torna muito parecida com a contabilidade que conhecemos e estudamos hoje.

No Brasil a contabilidade foi legalizada com o Decreto-Lei 9.295, de 27 de maio de 1946, o qual estabelece as atribuições dos profissionais de contabilidade. Nesse decreto, o profissional contábil era ainda conhecido como "guardalivros”, expressão que posteriormente foi extinta pela Lei 12.249 de II de junho de 20io. Pode-se considerar isso como um dos sinais de que o contador deixa de ser um mero registrador e cumpridor de obrigações fiscais e passar a ser um gestor de informações e analista financeiro e patrimonial. 
Atualmente, no Brasil, estamos vivendo o processo de convergência às normas internacionais de contabilidade, assunto que ainda gera muitas discussões a respeito de sua utilidade em relação à valorização da profissão contábil. Outra corrente de pensamento acredita que a convergência do Brasil às normas internacionais de contabilidade estaria desvalorizando a profissão, pois nem toda norma internacional de contabilidade estaria adaptada completamente à legislação brasileira.

Independentemente se benéfica ou não à valorização da profissão contábil, a convergência às normas internacionais de contabilidade é realidade de todo contador e, com certeza, um marco na história da contabilidade brasileira. A evolução da contabilidade e do profissional contábil está intrinsecamente ligada ao crescimento da economia, das ciências, da tecnologia, entre outros aspectos. O crescimento da contabilidade também está ligado ao ambiente, este sempre em constante mudança.

\section{ÁREAS DE ATUAÇÃO}

O contador dispõe de um gigantesco mercado de trabalho, e pode atuar em inúmeras áreas, visto que o presente estudo se baseia, principalmente, em aspectos regulamentares. Segue, abaixo, as áreas de atuação e funções do profissional contábil segundo a Resolução CFC 560/83:

Art. $2^{\circ}$ - O contabilista pode exercer as suas atividades na condição de profissional liberal ou autônomo, de empregado regido pela CLT, de servidor público, de militar, de sócio de qualquer tipo de sociedade, de diretor ou de conselheiro de quaisquer entidades, ou em qualquer outra situação jurídica definida pela legislação, exercendo qualquer tipo de função.Essas funções poderão ser as de: analista, assessor, assistente, auditor, interno e externo, conselheiro, consultor, controlador de arrecadação, “controller”, educador, escritor ou articulista técnico, escriturador contábil ou fiscal, executor subordinado, fiscal de tributos, legislador, organizador, perito, pesquisador, planejador, professor ou conferencista, redator, revisor (CONSELHO FEDERAL DE CONTABILIDADE, 1983). 
Marion (2005) acredita que a profissão contábil tenha, aproximadamente, 30 especializações, abrindo um leque de escolha conforme o dom de cada um: além de contador, pode ser auditor interno, perito, consultor, controller, planejador tributário, auditor independente, analista financeiro, contador de custo, contador gerencial, atuário, empresário contábil, investigador de fraudes, professor, pesquisador, parecerista, conferencista, contador público, agente fiscal de renda, oficial contador, arbitragem, etc. A fim de resumir essa questão e facilitar o entendimento, Marion (2005) apresenta uma relação referente às principais funções do contador, conforme afigura I:

Figura I - Principais funções do contador.

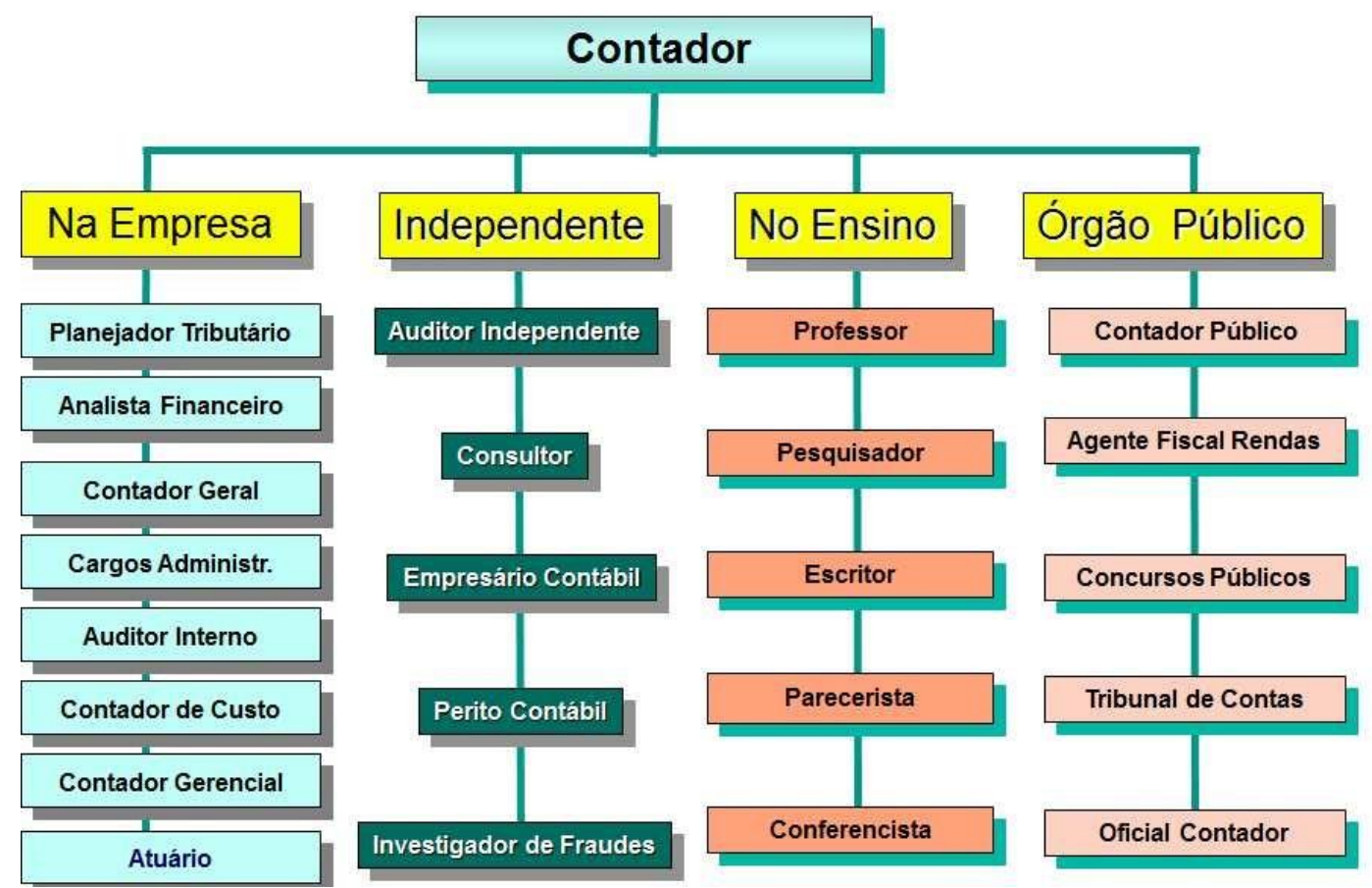

Fonte: Marion (2005, Internet, s. p.).

Esse profissional está relacionado com diversos usuários, estes, podem se diferenciar por finalidades, destacadas por Ribeiro (1997, p. 36): fins econômicos; socioeconômicos; e sociais. Outra finalidade de grande relevância é aquela imposta pela legislação, o que praticamente obriga as empresas a utilizarem os serviços 
contábeis, porém, independentemente se imposta por aspectos legais, ou não, toda instituição precisa dessa ciência, o que amplia suaárea de atuação e destaca a profissão.

O contabilista é profissional habilitado a trabalhar em diversas áreas, porém, também é necessário lembrar o que bem evidencia a Fipecafi (1997, p. 76) "da mesma forma que quaisquer outros profissionais, de acordo com os conhecimentose a capacidade que possuem, os contabilistas podem atuar em outras áreas que não aquelas diretamente relacionadas com a contabilidade.” Diante das inúmeras possibilidades que o profissional contábil tem a seu dispor, cabe a cada profissional optar pela que melhor lhe convém, lembrando que as responsabilidades diferem dependendo da área de atuação escolhida

\section{ÉTICA E A VALORIZAÇÃO DA PROFISSÃO}

O papel do contabilista é suprir as informações desejadas pelos seus usuários, e dependendo da informação prestada, esses usuários poderão tomar atitudes em diferentes direções; nesse sentido, para alcançar o objetivo da contabilidade. Lopes de Sá (2004, p. 144) também concorda que a aplicação de um padrão de condutas é importante para o profissional, inclusive para aprimorar a qualidade de seus serviços. Esse mesmo autor acredita que o valor profissional deve vir acompanhado do valor ético, para que exista uma imagem integral de qualidade. O CEPC prega o zelo pelo prestígio da classe, e esse pode ser obtido pela própria aplicação do código, como defende Vieira:

\footnotetext{
Ao saber de seu valor, poderá valorizar sua profissão. Ao valorizar sua profissão, saberá aplicar os princípios éticos, não como uma imposição legal ouorganizacional, mas como um instrumento fundamental de conduta, sem a qualsua existência perde o sentido. (2006, p. 22)
}

Vieira (2006, p. 22) percebe que a valorização profissional está intrinsecamente ligada a condutas morais e conclui que o profissional contábil provará sua importância e relevância para a sociedade, não apenas pela profissão que exerce, mas também pelo exemplo de profissionalismo e de conduta ética e moral. A perfeita conduta ética valoriza qualquer profissão, o profissional que 
desempenhar suas atividades com essa virtude, obterá notória honradez. Uma das maneiras mais eficazes para o profissional da contabilidade obter um padrão de condutas éticas é através da observância do CEP.

\section{ATUAÇÃO DO CONTADOR NA CONSULTORIA CONTÁBIL}

A consultoria contábil se apresenta como uma das áreas de atuação do contador. Para exercer essa função é preciso o profissional esteja registrado junto ao CRC do estado da federação onde pretende exercer tal atividade. O CFC entende a importância desse serviço para o mercado, e por isso mantém parcerias com contadores habilitados a fim de facilitar aos pequenos empreendedores o acesso a um consultor contábil.

DE ALMEIDA et. al (2017) identifica os altos custos e a escassez de profissionais consultores de contabilidade como as principais dificuldades enfrentadas pelas empresas quando estas decidem que precisam de uma consultoria contábil.

DIAS (2019) percebeu que muitas empresas preferem buscar dentro do seu quadro de funcionários por alguém que faça o trabalho de um consultor, no entanto, como lembra De Almeida et. al (2017), para exercer a função de consultor contábil, é preciso, além da qualificação em contabilidade, de uma série de competências administrativas que permitam ao consultor obter uma visão holística do negócio da empresa, principalmente na ausência de um plano de negócios préestabelecido e de um plano de carreira que sintetize a estrutura hierárquica da organização.

Almeida (2018) identifica a consultoria contábil como oportunidade de negócios para o profissional da contabilidade e como fator de sobrevivência para novos negócios, chegando a comparar a consultoria contábil com um "Plano de Saúde" empresarial que previne riscos de falência. É principalmente em tempos de crise econômica que a procura por ferramentas de controle e gestão aumentam a fim de "enxugar" custos. No entanto, a 
disponibilidade de profissionais não parece acompanhar esse movimento, e muitas empresas acabam por encerrar suas atividades por falta desse auxílio profissional.

Assim podemos perceber que embora haja demanda, faltam profissionais com formação disponíveis para atendê-la. Nesse sentido, seria importante investigar de maneira detalhada quais são as opções disponíveis nas instituições de ensino superior em relação à especialização em consultoria contábil, pois o acesso à essa especialização, ou mesmo uma base sólida durante a graduação em ciências contábeis, constitui o primeiro passo da carreira de um consultor.

\section{CONSIDERAÇÕES FINAIS}

A responsabilidade do profissional de contabilidade é sempre significativa e presente, tanto perante aspectos legais quanto diante de aspectos éticos. Seus trabalhos têm repercussão social, haja vista que a profissão contábil abrange diversas áreas da sociedade e possui grande utilitarismo. Não obstante, essa profissão pode ser desempenhada em ramos não diretamente relacionados à contabilidade, agigantando a amplitude mercadológica desse profissional.

Atualmente, o profissional contábil não se encontra valorizado de forma condizente com suas responsabilidades; exemplo claro disso é que o contador não figura entre os profissionais mais bem pagos em nosso país. Existem diversos meios para se subsidiar a valorização de uma profissão, e o estudo da responsabilidade perante aspectos legais e éticos é um deles, esse demonstrou, durante todo desenvolvimento deste trabalho, ser eficiente e de grande valia para mostrar o devido prestígio ao profissional contábil.

O contabilista é o profissional mais capacitado para demonstrar a situação financeira e patrimonial das empresas, e informações que são demonstradas de forma incorreta podem causar prejuízos, logo, esse profissional deve sempre mantersegurança quanto às informações que presta. Caso prejuízos devidos à falta de profissionalismo atinjam terceiros, o profissional poderá ser responsabilizado civilmente. 
Quesito essencial para a valorização da classe é a perfeita conduta ética, que está baseada em alguns alicerces, dos quais se pode destacar o zelo, a honestidade, a capacidade técnica, o sigilo e a independência. Para ajudar na aplicação dessa conduta, existe o CEPC. Á medida que o profissional aplica esses conceitos, mostra a verdadeira essência da contabilidade, valorizando a profissão.

Todo contabilista deve seguir determinadas premissas, porém, dependendo de sua área de atuação, poderão surgir outras responsabilidades. $\mathrm{O}$ valor de uma profissão acompanha o valor ético praticado pelos profissionais. $O$ contador precisa agir de forma independente, e não deve se deixar coagir por terceiros; também precisa manter sigilo acerca daquilo que lhe foi incumbido e confiado, para assegurar sua credibilidade. No cumprimento de suas atividades, deve primar pelo zelo, e suas ações, tomadas à luz da honestidade e fundamentadas em seu conhecimento técnico, esse deve ser atualizado e aprimorado constantemente.

Conclui-se que o profissional contábil é cobrado por diversos ditames legais, devendo ser observados todos esses aspectos no cumprimento de suas atividades, que poderão ensejar apuração dos responsáveis caso causem danos a outrem. Além dos aspectos legais, as atitudes do contador devem estar baseadas em preceitos éticos, e um bom instrumento para isso é o CEPC. Visto a amplitude de responsabilidade desse profissional, é inegável que ele pode (e deve) ser mais valorizado, pois quanto mais responsabilidade for atribuída à profissão, maior será seu valor.

\section{REFERÊNCIAS BIBLIOGRÁFICAS}

ALBRECHT, S.; SACK,R. Accounting Education: Charting a course Through a perilous future. Accounting Education Series, American Accounting Association, n. I6. 2000 . 
CONSELHO FEDERAL DE CONTABILIDADE. Abordagens éticas para o profissional contábil. Brasília: CFC, 2003.

DE ALMEIDA, Leonardo Soares Francisco et al. A consultoria contábil como forma de atuação profissional. Uma análise epistemológica. PESQUISA \& EDUCAÇÃO A DISTÂNCIA, n. Io, 2017.

ALMEIDA, Leonardo Soares Francisco de et al. A Consultoria Contábil como Oportunidade de Negócios Profissionais-um Estudo Documental. Pensar Contábil, v. 20, n. 72, 2018.

DIAS, Naime Modesto. As ações da consultoria contábil e financeira nas pequenas e médias empresas para a tomada de decisão. 2019.

FIPECAFI, Fundação Instituto De Pesquisas Contábeis, Atuariais e Financeiras ; LISBOA, Lázaro Plácido (Coord.).Ética geral e profissional em contabilidade.2.ed. São Paulo: Atlas, 1997 .

FREZATTI, F., AGUIAR, A.B., GUERREIRO, R. Diferenciações entre a contabilidade financeira e a contabilidade gerencial: uma pesquisa empírica a partir de pesquisadores de vários países. Revista de Contabilidade e Finanças, São Paulo, n. 44, p. 9-22, mai-ago. 2007.

HENDRIKSEN, Eldon S.; VAN BREDA, Michael F. Teoria da contabilidade. São Paulo: Atlas, 1999 .

HOWIESON, B. Accounting practice in the new millennium: is accounting education ready to meet the challenge? The British Accounting Review, n. 35, n. 2, p. 69-103. 2003. 
HUMPREY, C. In the aftermath of crisis: Reflections on the principles, values and significance of academic inquiry in accounting: Introduction. European Accounting Review. v. 14, n. 2, p. 341-351. 2005.

LOPES DE SÁ, Antônio. Contabilidade \& Novo Código Civil. Curitiba: Juruá, 2005.

MARION, José Carlos. Contabilidade, uma profissão empolgante. Disponível em

MIRANDA, C.S, RICCIO, E.L., MIRANDA, R.A.N.M. Atividades da Contabilidade Gerencial Sob a ótica de Docentes e Profissionais de Mercado. Revista Ambiente Contábil - UFRN - Natal-RN. v. 5. n. I, p. II2 - I3I, jan./jun. 2013.

RIBEIRO, O.M. Contabilidade geral: fácil. São Paulo: Saraiva, 1997.

VIEIRA, M.G A ética na profissão contábil. São Paulo: Thomson, 2006. 